\title{
ONLINE-OFFLINE. LAS GARANTÍAS PARA EL ACCESO A INTERNET Y PARA LA DESCONEXIÓN, BLOQUEO, FILTRADO Y OTRAS RESTRICCIONES DE LA RED Y SUS CONTENIDOS
}

LORENZO COTINO HUESO 


\section{SUMARIO}

I.- Las garantías híbridas del acceso a internet. II.- La variada regulación internacional, europea y española de las restricciones de acceso a internet. III.- Las garantías frente a las restricciones de acceso, bloqueo o filtrado de internet. IV.- Especiales garantías judiciales, de autoridades independientes y de transparencia. V.- Para concluir. La inconstitucionalidad del «apagón», «mordaza» o «155» digital aprobado con el Real Decreto-ley 14/2019 


\title{
ONLINE-OFFLINE. LAS GARANTÍAS PARA EL ACCESO A INTERNET Y PARA LA DESCONEXIÓN, BLOQUEO, FILTRADO Y OTRAS RESTRICCIONES DE LA RED Y SUS CONTENIDOS
}

\author{
LORENZO COTINO HUESO ${ }^{1}$ \\ Investigador de la Universidad Católica de Colombia. Catedrático de Derecho \\ Constitucional de la Universitat de Valencia
}

\section{I.- LAS GARANTÍAS HÍBRIDAS DEL ACCESO A INTERNET}

\section{1.- Un derecho de acceso a internet muy vinculado a las libertades informativas}

En las últimas dos décadas, se ha ido afirmando un derecho de acceso a internet (ius comunicationis) $)^{2}$. Así, se ha ido reconociendo paralelamente en el plano internacional de Naciones Unidas, europeo y nacional. Se trata de la garantía del acceso como libertad esencial muy vinculada a las libertades informativas, - aunque no excluyente de otros derechos. Como punto de partida, la STEDH Times Newspapers Ltd v.

1 Área de Derecho Constitucional. Facultad Derecho. Universidad de Valencia. Avda. de los Naranjos s/n. 46022-Valencia. Email: cotino@uv.es El presente estudio es resultado de investigación del proyecto «Derecho y Big Data», Grupo de Investigación en Derecho Público y TIC como investigador de la Universidad Católica de Colombia. De igual modo, en el marco del proyecto «La regulación de la transformación digital y la economía colaborativa» PROMETEO/2017/064 y MICINN Retos «Derechos y garantías frente a las decisiones automatizadas... (RTI2018-097172-B-C21, pendiente), al igual que de la Estancia de investigación ayuda Generalitat (AEST/2019/013).

2 Prontamente en España, Corredoira Alonso, L., «Lectura de la Declaración Universal de Derechos Humanos de 1948 en el paradigma de la nueva Sociedad de la Información. Estudio específico del artículo 19, en Cotino Hueso, L. (2007), Libertad en internet. La red y las libertades de expresión e información, Tirant lo Blanch, Valencia. El tema sin perjuicio de estudios en 2009, lo abordé con profundidad en «Las obligaciones del Estado: el nuevo derecho fundamental de acceso a internet y las garantías a partir de la redefinición de las clásicas libertades informativas», en AA.VV. (2015), La responsabilidad del Estado por la utilización de las tecnologías de la información y la comunicación (TIC), Universidad Católica de Colombia, Bogotá, págs. 51-94. (acceso en Academia.edu).

(C) UNED. Revista de Derecho Politico 
Reino Unido 10 de marzo de 2009 ( $\$$ 27) afirmó que «En vista de su accesibilidad y su capacidad para almacenar y comunicar grandes cantidades de información, Internet juega un papel importante en mejorar el acceso del público a las noticias y facilitar la difusión de información en general.» La Decisión n ${ }^{\circ}$ 2009-580 de 10 de junio del Consejo Constitucional francés ${ }^{3}$ respecto de la polémica ley HADOPI I ${ }^{4}$ asentó con rotundidad la premisa «En el estado actual de los medios de comunicación y con respecto al desarrollo generalizado de los servicios de comunicación pública en línea así como a la importancia que tienen estos servicios para la participación en la vida democrática y la expresión de ideas y opiniones, este derecho implica la libertad de acceder a estos servicios». ( $\left.\mathrm{n}^{\circ} 12\right)$.

El TEDH en sus más importantes sentencias sobre internet ${ }^{5}$, ha dejado claro que el artículo $10 \mathrm{CEDH}$ se aplica a Internet como medio de comunicación ${ }^{6}$. Incluso añade el TEDH que así es «sea cual sea el tipo de mensaje e incluso cuando se utiliza con fines comerciales» ${ }^{7}$. La importante Recomendación del Consejo de Europa de 2016 (CDE 2016) ${ }^{8}$, parte de la premisa de que el artículo 10 CEDH se aplica tanto offline como online ( $\left.{ }^{\circ} 1.1\right)$.

Señalaba V. Frosini ya en 2000 que el derecho de acceso a Internet permitiría la materialización de un auténtico derecho a constituir relaciones, transmitir y solicitar informaciones, y de poder (incluso) disponer autónomamente del entero conocimiento humano (científico, cultural, etcétera) sito en Internet ${ }^{9}$. Y como señala recientemente T. E. Frosini, como «nuevo modo de ser del constitucionalismo» el derecho de acceso a Internet implica una nueva forma de libertad de comunicar, por tanto, como libertad de transmitir y de recibir. Ya no es sólo el ejercicio de la libre manifestación del pensamiento «sino sobre todo la facultad de éstos de constituir una relación, de transmitir y requerir informaciones, de poder disponer sin límites del nuevo poder de conocimiento conferido por la telemática.» ${ }^{10}$ Holísticamente, no sólo implica la

3 Acceso en español https://www.conseil-constitutionnel.fr/es/decision/2009/2009580DC.htm

4 Acrónimo de Haute autorité pour la diffusion des œuvres et la protection des droits sur internet. Una autoridad administrativa a la que se facultaba con sancionar con la restricción de acceso a internet.

5 STEDH Ahmet Yildırım c. Turquía, de 18 de diciembre de 2012 § 48 y STEDH Delfi AS v. Estonia, de 16 de junio de 2015 (Gran Sala), § 127 y 131.

6 Por todos, cabe seguir el análisis del TEDH por Consejo de Europa, Internet: case-law of the European Court of Human Rights, Research Division, Estrasburgo, junio 2015. Acceso en https://www.echr. coe.int/Documents/Research_report_internet_ENG.pdf

7 STEDH Ashby Donald y otros c. Francia, 10 de enero de 2013, § 34.

8 Recomendación CM / Rec (2016) 5 del Comité de Ministros a los Estados miembros sobre la libertad en Internet (aprobada el 13 de abril) https://search.coe.int/cm/Pages/result_details.aspx?ObjectId=09000016806415fa\#_ftn1

9 Frosini, V. (2000), «L'orizzonte giuridico dell'Internet», Il Diritto dell'Informazione e dell'Informatica, núm. 2/2000, pp. 271-280, p. 276, sigo por Sánchez Barrilao, J. F. (2016), «El futuro jurídico de internet: una aproximación constitucional a la neutralidad de la red», en ReDCE núm. 26. JulioDiciembre, acceso en https://www.ugr.es/ redce/REDCE26/articulos/06_BARRILAO.htm\#138bis

10 Frosini, T. E. (2018), «Internet y democracia», en ReDCE núm. 30. Julio-Diciembre, (trad. J. F. Sánchez Barilao) acceso en https://www.ugr.es/ redce/REDCE30/articulos/03_FROSINI.htm 
libertad de acceso y utilización, sino también obligaciones prestacionales de garantía de dicho acceso, así como toda una panoplia de garantías frente a las restricciones. Las múltiples facetas de este nuevo derecho se articulan en la concurrencia de una híbrida amalgama de derechos subjetivos, fundamentales y no fundamentales, ya bajo una garantía subjetiva y negativa más clásica, así como especialmente de obligaciones positivas a través de desarrollos regulatorios diversos.

\section{2.- Un derecho con obligaciones positivas para el Estado como la garantía de acceso universal}

Este derecho de acceso incluye como uno de sus contenidos una dimensión prestacional: la garantía del acceso efectivo a internet con el correlato de la obligación Estatal a una «acción positiva fáctica», a modo de nuevo derecho social ${ }^{11}$. El reconocimiento de esta dimensión positiva y prestacional a partir de las libertades informativas resulta algo relativamente novedoso. No obstante, no es un reconocimento homogéneos puesto que esta dimensión prestacional se va destilando a partir de diversos derechos fundamentales, o se va reconociendo jurídicamente por medio en textos normativos de diferente naturaleza (constituciones, normativa europea, leyes, estatutos de autonomía, etc.). Así, en Estonia el artículo 5 de su Ley de Telecomunicaciones febrero de 2000 declaró el derecho de acceso a internet. En 2001 la Constitución griega reconoció en su artículo 5 un derecho y obligaciones del Estado para garantía del acceso. Y como luego se comenta, desde 2002 se reconoció el acceso universal en la UE (Directiva 2002/22/CE) iniciando toda una regulación de telecomunicaciones para el acceso a internet. Entre tales regulaciones, Finlandia reconoció el 2003 el acceso universal y en 2009 el «derecho básico» al acceso a Internet de una banda ancha de 1 MB como mínimo y de 100 Mb en 2015.

En clave internacional se afirmó el «derecho de acceso como acceso universal»a partir del artículo 19 de la Declaración Universal de Derechos Humanos interpretado por Naciones Unidas en la Declaración de Ginebra de 2003 (apartado 3 y números 24 a 28) y la Declaración de Principios Túnez de $2005^{12}$. Después, la importante Declaración conjunta sobre libertad de expresión e internet de 1 de junio de $2011^{13}$ (en adelante Declaración de 2011) subrayó «obligación positiva de facilitar el acceso

11 Arango, R. (2005), El concepto de derechos sociales fundamentales, Legis-UNAL Colombia, Bogotá, págs. 55 y 110 y ss. Por todos y de acceso completo, los trabajos de Escobar en Escobar Roca, G., (Dir.) (2012), Derechos sociales y tutela antidiscriminatoria, Thomson-Aranzadi, Cizur Menor https://dialnet. unirioja.es/servlet/libro? codigo $=577352$

12 Declaración de Ginebra, 2003, Cumbre Mundial sobre la Sociedad de la Información; Declaración de Principios de la Segunda Fase de esta Cumbre, celebrada en Túnez en noviembre de 2005, conocida como Compromiso de Túnez, que incluye un Plan de Acción sobre la Sociedad de la Información.

13 De relatores de libertad de expresión, incluyendo la ONU y la OEA. http://www.oas.org/es/cidh/ expresion/showarticle.asp? artID $=849 \& 1 \mathrm{ID}=2$

(C) UNED. Revista de Derecho Politico 
universal a Internet» ( $n^{\circ} 6$ a) y unos mínimos de acción ${ }^{14}$. En 2011 el TEDH afirmó que el Artículo $10 \mathrm{CEDH}$ debe interpretarse como una imposición a los Estados de la «obligación positiva de crear un marco regulatorio apropiado para garantizar la protección efectiva de la libertad de expresión de los periodistas en Internet ${ }^{15}$. Ello se aprecia con claridad en la reciente Declaración conjunta de los relatores de 10 de julio de $2019^{16}\left(\mathrm{n}^{\mathrm{o}} 1\right)$. Otras resoluciones internacionales de $2011^{17}$ y 2012 declararon la protección del acceso a internet vinculado especialmente a la libertad de expresión ${ }^{18}$, destacando también la Corte Suprema de Costa Rica el 30 de julio 2010 reconoció el derecho fundamental de acceso a internet con obligaciones para el Estado $^{19}$. Y la Declaración del Presidente de los Estados Unidos Barack Obama de 10 de noviembre de $2014^{20}$ reafirmaría el carácter esencial de internet para la economía y la democracia. En 2019, los relatores de libertad de expresión exhortan a los estados a «Reconocer el derecho al acceso y el uso de internet como un derecho humano y una condición esencial para el ejercicio del derecho a la libertad de expresión.» ( $n^{\circ} 2$. a).

La garantía prestacional del derecho de acceso ha tomado cuerpo a través del «acceso universal» ${ }^{21}$. Más allá de un reconocimiento como derecho subjetivo, humano o fundamental, el acceso se ha traducido especialmente en un régimen de obligaciones establecidas en la regulación de las telecomunicaciones. En la Unión Europea ya en documentos de 1999 y 2000 de la Comisión (eEurope) era un objetivo el acceso universal a precio asequible para todo usuario con calidad y con independencia de la localización. Su regulación básica se llevó en la Directiva 2002/22/CE de «servicio universal», cuyo objeto era reconocerlo y con garantías de calidad (art. $1.1^{\circ}$ y $2^{\circ}$ ). Los

${ }^{14}$ Así, «establecer mecanismos regulatorios «, creación de «puntos de acceso público», asegurar «el acceso equitativo a Internet para personas con discapacidad y los sectores menos favorecidos» y para todo ello, «adoptar planes de acción detallados» (6 e).

15 STEDH 5 de mayo de 2011, Comité Editorial de Pravoye Delo y Shtekel v. Ucrania.

16 Naciones Unidas (ONU), Declaración Conjunta del Vigésimo Aniversario: Desafíos para la Libertad de Expresión en la Próxima Década, 10 Julio 2019, https://www.refworld.org.es/docid/5d30a7d84.html

17 Informe del Relator Especial a la Asamblea de Naciones Unidas de 16 de mayo de 2011 sobre la promoción y protección del derecho a la libertad de opinión y de expresión, Frank La Rue http://www. un.org/ga/search/view_doc.asp?symbol=A/HRC/17/27\&Lang=S

18 Resolución del Consejo de Derechos Humanos ONU de 5 de julio de 2012 «Promoción, protección y disfrute de los derechos humanos en Internet» http://ap.ohchr.org/documents/S/HRC/d_res_dec/A_ HRC_20_L13.pdf

19 Decisión del 18-6-2010 (Expediente 10-003560-0007-CO) de la Sala Constitucional de la Corte Suprema de Justicia de Costa Rica.

20 «Un internet abierto es esencial para la economía estadounidense, y cada vez más en nuestro modo de vida. Reduciendo el costo de lanzar una nueva idea, encendiendo nuevos movimientos políticos, y uniendo cada vez más a las comunidades, internet ha sido uno de las influencias más democratizadoras que el mundo nunca ha conocido.» https://obamawhitehouse.archives.gov/the-press-office/2014/11/10/ statement-president-net-neutrality

${ }^{21}$ Se define como «un conjunto mínimo de servicios, definido en la Directiva 2002/22/CE (Directiva servicio universal), de una calidad determinada y que esté disponible para todo usuario con independencia de su localización geográfica y, a la vista de las condiciones nacionales específicas, a un precio asequible» (art. 2. J Directiva 2002/21/CE, marco). 
artículos 3 y 4 , sin afirmar expresamente que se trataba de un derecho subjetivo, señalaron las obligaciones de los Estados y los principios básicos de objetividad, transparencia, no discriminación y proporcionalidad (art. 3. $1^{\circ}$ y $2^{\circ}$ y $\left.4.2^{\circ}\right)^{22}$. En 2018 , el Código Europeo de Comunicaciones Electrónicas (Directiva 2018/1972) delimita el alcance del acceso universal (Considerando 214) y se reconoce que el acceso «ha adquirido una importancia crucial para la sociedad y la economía en general» esenciales (Considerando 213). El art. 1. $2^{\circ}$ del Reglamento (UE) 2015/2120 de 25 de noviembre de 2015 expresa como «derecho» el acceso a internet (Considerando 6).

\section{3.- La seria regulación del acceso en las telecomunicaciones y el simbolismo y frivolidad en su reconocimiento como derecho en otras leyes}

En España el derecho de acceso a internet ha gozado de una importante y seria regulación jurídica en el ámbito de las telecomunicaciones en el marco del servicio universal. Sin embargo, fuera de ahí, la regulación es básicamente simbólica, cuando no frívola y huera.

Prontamente se reconoció en España el derecho de acceso en la histórica y simbólica declaración de derechos de las Conclusiones de la Comisión Especial de Redes Informáticas del Senado de España de $1999^{23}$. A partir de la normativa europea, el acceso funcional a internet ya se incorporó a través de la Ley 34/2002, de 11 de julio modificando la Ley General de Telecomunicaciones (LGT, entonces Ley 11/1998, de 24 de abril). Especialmente quedó recogido en la posterior LGT (Ley 32/2003, de 3 de noviembre, arts. 22-24) y actualmente en la actual LGT Ley 9/2014, de 9 de mayo. Aunque se parte del principio de libre prestación de servicios, los operadores tienen importantes obligaciones en su explotación. Y especialmente han de cumplir las obligaciones de servicio público del «servicio universal» (arts. 25 - 27 LGT) ${ }^{24}$. Aunque no se expresa como un derecho subjetivo, este régimen es el que ciertamente ha supuesto la garantía de acceso a internet.

Más allá de la regulación de comunicaciones, otras normas tienen un especial valor simbólico, especialmente para la consideración de derecho subjetivo al acceso.

${ }^{22}$ Los «Estados miembros velarán por que los servicios que se enumeran en el presente capítulo se pongan, con una calidad especificada, a disposición de todos los usuarios finales en su territorio, con independencia de la situación geográfica y, en función de las circunstancias nacionales específicas, a un precio asequible.» (art. 3.1) y bajo el «enfoque más eficaz y adecuado para garantizar la aplicación del servicio universal, respetando los principios de objetividad, transparencia, no discriminación y proporcionalidad» $\left(\operatorname{art} .3 .2^{\circ}\right)$. Por lo que ahora más interesa, se reconocía él, el «Suministro de acceso desde una ubicación fija» y con él «deberá permitir a los usuarios finales [...] transmisiones de datos a velocidades suficientes para acceder de forma funcional a Internet, teniendo en cuenta las tecnologías dominantes utilizadas por la mayoría de los abonados y la viabilidad tecnológica.» (art. 4. $2^{\circ}$ ).

23 Acceso en http://www. internautas. org/documentos/decla_dere. htm

${ }^{24}$ Ver, Carlón Ruiz, M. (2015), «Las obligaciones de servicio público, en especial, el servicio universal de telecomunicaciones», en José Vida Fernández y otros (dir.), Derecho de las telecomunicaciones: adaptado a la Ley 9/2014, de 9 de mayo, General de Telecomunicaciones, Thomson Reuters-Civitas, pp. 593-649.

(C) UNED. Revista de Derecho Político 
Así, en 2006 se expresó un «derecho de acceso a las nuevas tecnologías» en el art. 19. $2^{\circ}$ del Estatuto de la Comunidad Valenciana ${ }^{25}$, copiado en Andalucía (art. 34) y en los estatutos catalán, balear o aragonés recogido como un mandato de promoción. La Ley orgánica 3/2018, de 5 de diciembre sigue sin pasar del plano simbólico. A última hora y sin la calidad técnica que hubiera correspondido, esta ley incluyó como injerto en la legislación de protección de datos un Título X de «Derechos digitales» ${ }^{26}$. Se afirma en su Exposición de Motivos que sería deseable «Una deseable futura reforma de la Constitución debería incluir entre sus prioridades la actualización de la Constitución a la era digital y, específicamente, elevar a rango constitucional una nueva generación de derechos digitales.» Por lo que ahora interesa, el artículo 81 incluye el «Derecho de acceso universal a Internet». Su texto, de naturaleza básicamente promocional, no aporta nada más que su afirmación como «derecho». Además, para el legislador orgánico este derecho de acceso universal no es desarrollo orgánico de un derecho fundamental (Disp. Final $1^{\mathrm{a}}$ ). Tampoco el derecho a la neutralidad lo es (art. 80). Por lo demás y como es lógico, estos derechos pese a estar en la misma ley no gozan de las garantías propias al derecho de protección de datos (art. 2. $1^{\circ}$ ).

\section{4.- La neutralidad de la red y restricciones al acceso a un internet abierto}

La neutralidad de internet es un elemento estructural y esencial que en buena medida ha venido ligada al derecho de acceso a un internet abierto ${ }^{27}$. Tim Wu afirmó en 2003 la «Internet Freedom» («Libertad para acceder a contenido, libertad para usar aplicaciones, libertad para conectar dispositivos personales y libertad para obtener información del plan de servicio») vinculada al acceso y en 2004 identificó la neutralidad como «un derecho general al uso de red sin restricciones» ${ }^{28}$. Si el servicio universal garantiza el acceso asequible, la neutralidad en buena medida implica la garantía de un trato equitativo y no discriminatorio del tráfico en la prestación de servicios de acceso a internet ${ }^{29}$. En principio, supone que los operadores por razones comerciales no puedan manipular el tráfico para priorizar, ni restringir, ni bloquear el acceso por los usuarios finales a contenidos, aplicaciones y servicios sobre internet.

25 Lo analizo en «Artículo 19. Desarrollo equitativo, territorialmente equilibrado y sostenible y derecho de acceso a las nuevas tecnologías», Garrido Mayol, V. (dir.) (2013), Comentarios al Estatuto de Autonomía de la Comunitat Valenciana, Tirant lo Blanch, págs. 375-393, acceso en internet.

26 Procedía de Proposición no de Ley del Grupo Parlamentario Socialista 161/001720 presentada el 27 de marzo de 2017, también muy inconcreta.

27 Por todos, Robles Carrillo, M. (2019), «El modelo de neutralidad de la red en la Unión Europea: alcance y contenido», en Revista de Derecho Comunitario Europeo, No 63, págs. 449-488, de especial interés la evolución del concepto, pp. 466 y ss.

28 Se sigue por Ibídem p. 462.

29 Vida Fernández, J. (2016), «Las garantías para el acceso a una internet abierta en el Reglamento (UE) 2015/2120: una batalla perdida para la neutralidad de la red», en Revista General de Derecho Europeo, ‥ 40, págs. 96-124, p. 100. 
Así pues, la falta de neutralidad dificulta el acceso por los usuarios, así como el ejercicio igual de sus derechos a través de la red ${ }^{30}$.

El encaje jurídico de la neutralidad es variado. La neutralidad se ha reconocido en importantes declaraciones ${ }^{31}$ y se ha vinculado a la libertad de expresión, como en Colombia $^{32}$. Cuenta con su regulación propia, así, con carácter general en Chile en 2010, en 2011 en Países Bajos, en 2014 en Brasil, en Rusia en 2016 o la fuerte regulación en India en 2018. En EEUU se incluyó como principio desde 2005 y se dio un fuerte impulso con la mencionada declaración de Obama de $2014^{33}$, si bien en 2017 bajo presidencia de Trump se ha dado el fin de la neutralidad ${ }^{34}$.

En la UE el Reglamento 2015/2120 además de afirmar el derecho de acceso (art. 1. $2^{\circ}$ ), por cuanto a la neutralidad, regula la obligación de tratar todo el tráfico de manera equitativa, sin discriminación, restricción o interferencia, con independencia del emisor y el receptor, el contenido, las aplicaciones o servicios o el equipo terminal empleado (art. 3.3. 1. ${ }^{\circ}$ ) y la obligación de no bloquear, ralentizar, alterar, restringir, interferir, degradar, ni discriminar entre contenidos, aplicaciones o servicios concretos o categorías específicas (art. 3.3. 3.'). Ahora bien, caben excepciones a estas obligaciones, «en caso necesario y únicamente durante el tiempo necesario». Por lo que ahora interesa, el motivo puede ser legislación o resoluciones judiciales o de autoridades nacionales (letra a) o la «Integridad y seguridad de redes y servicios» (art. 3.3. b). Se trata de excepciones bajo interpretación estricta sujeta al requisito de proporcionalidad. ${ }^{35}$ Así pues, la garantía del acceso a internet es poliédrica y también se articula a través del importante principio y regulación de la neutralidad de la red, que tiene también un encaje jurídico híbrido.

\section{II.- LA VARIADA REGULACIÓN INTERNACIONAL, EUROPEA Y ESPAÑOLA DE LAS RESTRICCIONES DE ACCESO A INTERNET}

Hasta el momento se ha visto la emergencia del acceso a internet, si se me permite, en positivo, como derecho humano y fundamental en construcción y como ele-

\footnotetext{
30 Sánchez Barrilao, J. F., «El futuro jurídico de internet... cit.

31 Así, en Noruega la «Network neutrality Guidelines for Internet neutrality» de 2009 https://bit. ly/2QBFRju o las Conclusiones del Consejo Europeo de la UE sobre internet abierto y neutralidad de 13 de diciembre de 2011, https://bit.ly/2MnLtQ8 La mencionada Declaración de 2011 la recoge como ${ }^{\circ} 5$.

32 La Corte Constitucional colombiana en su Sentencia T-277/15 considera que la neutralidad es un principio constitucional derivado de la libertad de expresión. En ese caso se identificaba la neutralizad con que no es preciso un control previo de contenidos por el buscador Google.

33 Así, aunque el principio de una internet abierta se proclama en 2005, en 2010 tuvo un impulso regulatorio y especialmente en 2015, la FCC adoptó la Open Internet Order.

${ }^{34}$ No obstante, bajo mandato de Trump las reglas básicas de la neutralidad se revocaron en 2017 mediante la Restoring Freedom Internet Order. Sánchez Barrilao J. F. (2020), El internet en la era Trump: aproximación constitucional a una nueva realidad, Universidad Nacional Autónoma de México, IIJ-BJV, 2020 https://revistas.juridicas.unam.mx/index.php/derecho-informacion/issue/archive

35 Ver Robles Carrillo, M., «El modelo de neutralidad ... cit. pp. 479 y 480.
}

(C) UNED. Revista de Derecho Politico 
mento y principio básico especialmente en el ámbito del Derecho de las comunicaciones. El acceso a internet también se conforma jurídicamente en negativo, esto es, apreciando la variada y una vez más híbrida regulación de sus restricciones y, como luego se verá, las garantías frente a las mismas. Como a continuación se aprecia, el Derecho internacional en ciernes en la materia viene a reconocer la soberanía estatal para imponer restricciones de internet y entre los escasos límites muy tímidamente apunta posibles contenciones en razón de derechos humanos. En la diversa regulación de la UE el punto de partida es el acceso y las restricciones son la excepción. Eso sí, una excepción abierta a la determinación por los Estados por razones de seguridad pública y nacional. Y en la arena nacional, también son dispersas y variadas las regulaciones que permiten posibles restricciones del acceso a internet en forma de obligaciones para operadores de redes y servicios digitales. Como se dirá, se trata de un conjunto normativo en la sombra de la regulación de seguridad. Pese a su trascendencia, en buena medida pasa desapercibido por considerarse técnico y sectorial y porque es opaco al no regular con claridad el alcance de las restricciones y obligaciones que puede implicar.

\section{1.-La interrupción de las telecomunicaciones en perspectiva del Derecho internacional público}

En clave internacional, no parece haber dudas de que «un Estado ejerce control sobre la ciberinfraestructura y las actividades cibernéticas en su territorio, lo hace sobre la base del principio de soberanía.» (art. 62. $1^{\circ}$ Manual de Tallín ${ }^{36}$ ). El Preámbulo de la Constitución de la Unión Internacional de Telecomunicaciones (UIT) ${ }^{37}$ se inicia precisamente $« 1$. Reconociendo en toda su plenitud el derecho soberano de cada Estado a reglamentar sus telecomunicaciones». Su artículo 34 expresa el derecho [de los Estados] a interrumpir, de acuerdo con su legislación nacional, otras telecomunicaciones privadas (esto es, no públicas) que puedan parecer peligrosas para la seguridad del Estado o contrarias a sus leyes, al orden público o a las buenas costumbres.» Ello es así, aunque «no podrá suspender los servicios internacionales de comunicación cibernética en los que se basa una misión diplomática u oficina consular» (Manual de Tallín art. 34. $9^{\circ}$ ). Basta la comunicación inmediata a los demás Estados de la UIT

36 El llamado Manual de Tallin, es el texto mundial de referencia sobre la regulación de la ciberguerra y la ciberdefensa. Se su segunda edición, Schmitt, M. (Dir.) (2017), Tallinn Manual 2.0 on the International Law Applicable to Cyberoperations, Cambridge University Press. Se sigue la regla 62 y comentarios en pp. 271 y ss. Otro documento de referencia en la materia, [s.a] Droit international appliqué aux operations dans le cyberspace, Ministère des Armées, París, 2019 https://www.defense.gouv.fr/content/ download/565895/9750877/file/Droit + internat +appliqu\%C3\% A9+aux +op\%C3\% A9rations + Cyberespace.pdf Sobre el tema, Robles Carrillo, M., El régimen jurídico de las operaciones en el ciberespacio: estado del debate, IEE, 101/2019 12 de noviembre de 2019, acceso en http://www.ieee.es/ Galerias/fichero/docs_opinion/2019/DIEEEO101_2019MARROB_legalciber.pdf

37 https://www.itu.int/council/pd/constitution-s.docx 
(art. 35 y art. 62 a) ${ }^{38}$ Cada Estado podrá «impedir la transmisión de una comunicación cibernética privada que parezca contraria a su legislación nacional, al orden público o a las buenas costumbres, o que sea peligrosa para su seguridad nacional.» (art. 62 . b) Manual). Ello sin perjuicio de las obligaciones de Derecho internacional y que le prohíban hacerlo en un caso particular, como las normas de derechos humanos (art. 62. $1^{\circ}$ Manual y comentario $9^{\circ}$ ). Se trata, pues, de una muy tímida referencia a posibles límites a las restricciones de acceso a internet.

Del reverso, los otros Estados «deben respetar la prerrogativa soberana» (comentario $1^{\circ}$ art. 62 Manual) de regular o suspender sus telecomunicaciones. Ello conlleva a considerar una usurpación ilícita (art. 4 Manual) «las actividades destinadas a eludir la suspensión» (comentario $6^{\circ}$ art. 62 Manual con relación al art. 34 C. UIT) $)^{39}$.

\section{2.- Restricciones al acceso en la normativa europea}

Las directivas y reglamentos europeos al tiempo que reconocen el acceso universal y neutralidad de internet están plagadas de excepciones. Así, se expresa la posibilidad de adoptar medidas justificadas por «orden público y de moralidad y seguridad públicas» (Directiva 2002/22/CE ), por «intereses esenciales de seguridad, para salvaguardar la seguridad y el orden públicos» (Directiva 2002/21/CE, Considerando 7). Cabe remitir a lo que se afirmará infra respecto de la llamada «previsión de libertad» del artículo 1.3 bis de la Directiva 2002/21/CE que se introdujo en 2009.

El Reglamento (UE) 2015/2120 de 25 de noviembre sobre acceso a una internet abierta también reconoce posibles excepciones por la UE o los Estados relacionadas con la licitud de los contenidos o por seguridad pública, incluidas medidas de bloqueo por Derecho penal. Se recuerda que las medidas restrictivas han de ser con las garantías del CEDH «incluidas sus disposiciones sobre la tutela judicial efectiva y las debidas garantías procesales.» (Considerando 13). También se indica que las medidas a adoptar, más allá de la gestión del tráfico «pueden ser necesarias para proteger la integridad y la seguridad de la red, por ejemplo para evitar ciberataques». (Considerando 14).

El Código Europeo de Comunicaciones Electrónicas (Directiva 2018/1972) se entiende «sin perjuicio» de las actuaciones emprendidas por los Estados miembros con fines de orden público y seguridad pública y de defensa» (art. 3 c). Entre otras cuestiones, se afirma que «En los casos excepcionales en que los Estados miembros decidan limitar la libertad de suministrar redes y servicios de comunicaciones electrónicas por motivos de orden público, seguridad pública o salud pública, deben

${ }^{38}$ El Art. 7(1) del Reglamento de Telecomunicaciones Internacionales de la UIT también ampara estas «suspensiones».

39 No obstante, una minoría del grupo de trabajo considera que en principio sí que es posible que un Estado suministre a distancia telecomunicaciones a otro Estado.

(C) UNED. Revista de Derecho Político

N. 108 , mayo-agosto 2020, págs. 13-39 
explicar los motivos de esa limitación.» (Considerando 117) ${ }^{40}$. Respecto de las medidas provisionales de urgencia se expresa la garantía de dar una oportunidad al afectado de expresar su punto de vista así como un plazo máximo y necesidad de ratificación (art. 30. $6^{\circ}$ ).

También en este ámbito, cabe seguir la Directiva (UE) 2016/1148 ${ }^{41}$, NIS (Network and Information Systems) y el Marco político de ciberdefensa de la Unión Europea, adoptado por el Consejo el 19 de noviembre de 2018 y el Reglamento (UE) 2019/881 ENISA.

Pues bien, todas esta restricciones y excepciones de la UE, toman cuerpo esencialmente en el ordenamiento jurídico interno español y, en particular, en la LGT y la nueva regulación por el Decreto-Ley 14/2019 que infra se analiza.

\section{3.- La regulación de seguridad en España que implica obligaciones para operadores de redes y servicios digitales}

En Derecho español las obligaciones en el ámbito de las telecomunicaciones por seguridad vienen impuestas por diversas normas. Se trata de una regulación que esencialmente determina qué órganos pueden imponer decisiones y obligaciones y cuáles, pero que no detalla materialmente el alcance que pueden tener tales decisiones ni su potencial carácter restrictivo para el acceso a internet y sus contenidos. Considero que en general, la regulación en abstracto no genera dudas de constitucionalidad, sino que las dudas se pueden dar especialmente por su aplicación concreta. Estas decisiones y obligaciones posiblemente restrictivas se dan en un entorno ciertamente opaco, tanto por los órganos que las adoptan y sus instrumentos como por el propio velo tecnológico ajeno al conocimiento generalizado. Ello, ciertamente no facilita su control.

Las «Tecnologías de la Información y las Comunicaciones» son un sector estratégico (art. 2 y Anexo I Ley 8/2011, de 28 de abril). La Comisión Nacional para la Protección de las Infraestructuras Críticas puede considerar que un operador de redes y telecomunicaciones sea considerado un «operador crítico». En este caso, el operador tiene la obligación de colaborar con las autoridades con el fin de optimizar la protección de las infraestructuras críticas. Para ello, deben elaborar planes, designar responsable y delegado de seguridad o facilitar inspecciones de las autoridades (art. 13 Ley 8/2011).

Asimismo y conjuntamente cabe tener en cuenta el Real Decreto-ley 12/2018, de 7 de septiembre, de seguridad de las redes y sistemas de información transpone la Directiva (UE) 2016/1148, NIS a fin de un elevado nivel común de seguridad en las redes y sistemas. Esta norma se aplica a los designados como operadores críticos de

\footnotetext{
${ }^{40}$ Ver también Considerandos 5 y 108.

41 Del Parlamento Europeo y del Consejo, de 6 de julio de 2016, relativa a las medidas destinadas a garantizar un elevado nivel común de seguridad de las redes y sistemas de información en la Unión.
} 
servicios de comunicaciones electrónicas y los recursos asociados (art. 2. 3 a). Igualmente, la norma se aplica a los «servicios digitales», en buena medida, mercados en línea, motores de búsqueda en línea y servicios de computación en nube y otros prestadores de servicios de la sociedad de la información que no sean pequeñas empresas (arts. 2. 1 b) y 3). El sistema es que los «operadores de servicios esenciales y los proveedores de servicios digitales deberán adoptar medidas adecuadas para gestionar los riesgos proporcionadas al nivel de riesgo» (Exposición de Motivos III). Especialmente el sistema genera obligaciones de notificación de incidentes en las redes para la prestación de servicios esenciales (art. 19). Además, la norma se remite a obligaciones a los operadores y prestadores que se detallan en normativa o instrucciones concretas que se dicten (arts. 16, 32 y 33). En principio, hay que considerar que estas normativas e instrucciones infralegales podrán implicar obligaciones, pero no restricciones a internet.

Lo mismo cabe concluir de la Ley 36/2015, de 28 de septiembre, de Seguridad Nacional. Esta ley no es nada concreta respecto de las obligaciones y acciones posibles a emprender, aunque no se excluye que las entidades privadas contribuyan a la seguridad nacional (art. 27. $5^{\circ}$ ), especialmente en el caso de «operadoras de servicios esenciales y de infraestructuras críticas» (art. $7.1^{\circ}$ ). El Gobierno determinará reglamentariamente o en su acción el alcance de dichas obligaciones y colaboración, que, en principio, no pueden implicar restricciones de derechos. También cabe recordar que en una «Situación de interés para la Seguridad Nacional» (art. 23. $3^{\circ}$ ) «se afrontará con los poderes y medios ordinarios de las distintas Administraciones Públicas y en ningún caso podrá implicar la suspensión de los derechos fundamentales y libertades públicas de los ciudadanos.» Ciertamente hay una indefinición de la posibilidad de restricciones -que no suspensión- de derechos en estas «situaciones» ${ }^{42}$, si bien considero que la aplicación de esta ley por sí misma no puede implicar una restricción del acceso a internet.

\section{III.- LAS GARANTÍAS QUE SE VAN DESTILANDO FRENTE A LAS RESTRICCIONES DE ACCESO, BLOQUEO O FILTRADO DE INTERNET}

Las posibilidades de afectar el acceso a internet son variadas y multiformes. Si se puede dudar del carácter de derecho humano o fundamental en clave del acceso a internet, considero que las garantías frente a las restricciones permiten percibir con nitidez la fibra constitucional o de derecho humano de la cuestión. La construcción jurisprudencial, especialmente europea, resulta un básico punto de partida que habría

${ }^{42}$ He analizado las posibilidades de restricción de derechos por esta ley en Cotino Hueso, L. (2020), «Los derechos fundamentales en tiempos del Coronavirus. Régimen general y garantías y especial atención a las restricciones de excepcionalidad ordinaria», en El Cronista, IUSTEL, , marzo-abril, pp. 88-101. Acceso en http://www.elcronista.es/El-Cronista-n\%C3\%BAmero-86-87-Coronavirus.pdf

(C) UNED. Revista de Derecho Político 
de tenerse en cuenta tanto por el legislador como la jurisprudencia nacional a la hora de actualizar las garantías de las libertades informativas.

\section{1.- Restricciones de acceso, bloqueo o filtrado de internet}

Hay una «tendencia mundial» ${ }^{43}$ al «filtrado», «bloqueo», «cierre», «apagón», «intervención», «cierre», «censura» de internet. Como señala Internet Society «desde el punto de vista del usuario, el término elegido es menos importante que el efecto: la imposibilidad de obtener acceso a una parte de Internet.» Si la censura tiene muy mala prensa, el «filtrado» «parece denotar una operación más simpática e inocua». Como se verá, lo mismo sucede a mi juicio con la terminología empleada por el nuevo artículo $4.6^{\circ} \mathrm{LGT}$, que parece inocua. Se afirma la conveniencia del término simple y directo de «bloqueo». ${ }^{44}$ García Mexía habla de «velos» (bloqueo político de contenidos) y «vallas» (por las grandes plataformas) ${ }^{45}$. Los «velos» pueden ser bloqueos directamente por las autoridades, tipo cuello de botella como Irán, o a través de los proveedores de servicios que siguen las instrucciones políticas del gobierno (es el modelo chino). Éste último modelo sí que está previsto también en países democráticos, aunque bajo regulación adecuada. Una receta bien conocida es ralentización deliberada de la red en países como Irán, Cuba o Venezuela ${ }^{46}$. Desde Internet Society se concluye que el bloqueo suele ser ineficiente, a menudo no es eficaz y, en general, perjudica involuntariamente a los usuarios con daños colaterales ${ }^{47}$.

\section{2.- Garantías generales y particulares en razón del CEDH}

Al mismo tiempo de una emergente dimensión prestacional que garantice el acceso, el derecho fundamental de acceso a internet ha llevado a que se destilen diversas garantías frente a la restricción o bloqueo del acceso. Es bien posible que la naturaleza de derecho fundamental del acceso a internet se perciba con mayor nitidez en razón de estas garantías. Las mismas no serían tan novedosas, sino que deben consi-

43 Internet Society, Perspectivas de Internet Society (ISOC) sobre el bloqueo de contenido en Internet: Visión general, Internet Society, marzo 2017, p. 4 acceso en https:/www.internetsociety.org/es/resources/ doc/2017/internet-content-blocking/

44 Internet Society, Perspectivas... cit. p. 5.

45 García Mexía, P. L. (2012), «El derecho de acceso a internet», en T. de la Quadra-Salcedo y J. L. Piñar Mañas (dirs.), Sociedad Digital y Derecho, págs. 397-416, pp. 401 y ss.

46 Baste recordar la ralentización de internet en 2006, 2009, 2010 y 2013 en Irán. O directamente «apagones» de internet en 2019 https://es.wikipedia.org/wiki/Censura_de_Internet_en_Ir\%C3\%A1n Véase ránking de restricciones en Speedtest Global Index. https://www.speedtest.net/global-index

${ }^{47}$ El bloqueo simplemente coloca una cortina frente al contenido subyacente que permanece en su lugar. Se afirma en general que «el método menos dañino es «atacar» el contenido y las actividades ilegales en el origen» y priorizar enfoques de cooperación y entornos de seguridad y filtros por los usuarios, Internet Society, Perspectivas... cit. p. 6 y pp. 22-23 
derarse como derivadas de la más clásica dimensión de libertad o negativa de las libertades informativas, con las garantías legales y judiciales que ello comporta. No hace falta acudir a un nuevo derecho fundamental, pero sí a actualizarlo y a dotar de una mayor claridad normativa y jurisprudencial.

El punto de partida es no caben restricciones generales a internet $\left(\mathrm{n}^{\circ} 2.1\right.$. CDE 2016) y toda restricción del acceso a internet debe cumplir los requisitos de todo límite a la libertad de expresión ${ }^{48}$. Asimismo, las declaraciones internacionales parten de que «La libertad de expresión se aplica a Internet del mismo modo que a todos los medios de comunicación» (Declaración 2011, 1 a). No obstante, la regulación debe estar modulada a las particularidades de la red ( $n^{\circ} 1$. c), si bien, por ello «no deben establecerse restricciones especiales al contenido de los materiales que se difunden a través de Internet.» (1. d). Sin embargo, el TEDH recuerda que el riesgo de daño que genera internet, especialmente a la vida privada, «es ciertamente mayor» que el que plantea la prensa ${ }^{49}$. Sobre esta base, es especialmente destacable la STEDH Ahmet Yildırım c. Turquía de 18 de diciembre de 2012. La misma fija algunos parámetros esenciales de la regulación del bloqueo de contenidos en internet (aps. 64-68):

- las restricciones previas al acceso no son necesariamente incompatibles con el CEDH.

- el marco legal debe establecer reglas precisas y específicas con respecto a la aplicación de restricciones preventivas sobre libertad de expresión.

- se requiere un marco legal que garantice un control estricto sobre el alcance de las prohibiciones.

- el marco legal debe establecer una revisión judicial efectiva que actúe a partir de las reglas específicas. La ponderación judicial es inconcebible sin el referido marco legal para evitar cualquier abuso de poder.

- Una mala normativa no satisface el requisito de predictibilidad y no brinda el nivel de protección que garantiza el Estado de Derecho de una sociedad democrática.

- La legislación debe imponer al juez que se adopte la medida menos restrictiva, de modo que bloquee el mínimo de contenidos posibles y, en principio, sólo se bloquee la web concreta.

- No puede ordenarse a los prestadores de internet que bloqueen contenidos sin discriminar entre los que son lícitos y los ilícitos.

- La medida que conlleva que grandes cantidades de información sean inaccesibles, restringe sustancialmente los derechos de los usuarios de Internet y «tuvo un efecto colateral significativo». Cualquier medida que se adopte requiere que se analice si se puede evitar acceder al contenido ilegal afectando a otros usuarios y contenidos.

48 Ello está claro en la Declaración 2011, no 1. a) y el CDE $2016\left(\mathrm{n}^{\circ} 1.1^{\circ}\right.$ y n 2.1 .4 y $\left.6^{\circ}\right)$.

49 STEDH Comité editorial de Pravoye Delo y Shtekel v. Ucrania, de 5 de mayo de 2011, § 63 y STEDH Węgrzynowski and Smolczewski v. Polonia, de 16 de julio de $2013 \S 98$.

(C) UNED. Revista de Derecho Político 
A estas reglas relativamente claras del TEDH pueden añadirse otras garantías generales y particulares en todo control de admisibilidad de las restricciones de acceso. Como reglas generales:

- «desconectar a las personas de Internet, como regla general, representa una restricción desproporcionada del derecho a la libertad de expresión» $\left(\mathrm{n}^{\circ} 2.5^{\circ}\right.$ CDE 2016). Así, debe darse un muy especial escrutinio respecto de interrupciones, reducciones de velocidad, filtrados públicos o privados o bloqueo de sitios enteros. Sin embargo, no se puede considerar que haya una prohibición en términos absolutos, como sostiene la Declaración de 2011.50

- El análisis de la proporcionalidad debe tener muy en cuenta en abstracto «la capacidad de Internet para garantizar y promover la libertad de expresión» (1. b Declaración 2011).

- Asimismo, la regulación debe estar modulada a las particularidades de la red (1. c), si bien, por ello «no deben establecerse restricciones especiales al contenido de los materiales que se difunden a través de Internet.» (1. d).

- Tanto para autoridades estatales como sector privado deben proyectarse las garantías del art. $10 \mathrm{CEDH}$ «para bloquear o restringir el acceso a una plataforma completa de Internet» $\mathrm{y}$ «filtrar o eliminar contenido de Internet» (2.2.1 ${ }^{\circ}$ y $\left.2^{\circ} \mathrm{CDE} 2016\right)$.

Entiendo que todos estos lineamientos resultan esenciales y básicos para la necesaria actualización de las libertades informativas y en particular con relación a las restricciones de acceso a internet.

\section{3.-La evolución respecto de los filtrados de internet en la UE}

Respecto de la posibilidad de establecer filtros, se ha pasado de la práctica prohibición de filtros generales y preventivos, incluso por mandato judicial, a la posibilidad del requerimiento judicial con requisitos. Y estamos en ciernes de que los filtros sean ya obligatorios.

Inicialmente las Sentencias TJUE de 2011 y 2012 ${ }^{51}$, no permitieron que judicialmente se impongan controles y filtrados técnicos y preventivos a prestadores de servicios y redes sociales, para evitar la comisión de ilícitos de propiedad intelectual

${ }^{50}$ La Declaración 2011 viene prácticamente a prohibir estas medidas, algo que aquí no se comparte. Así, si se trata del bloqueo de sitios enteros, redes, etc. ( $\left.n^{\circ} 3\right)$, es «una medida extrema—análoga a la prohibición de un periódico o una emisora de radio o televisión» aunque afirma que excepcionalmente cabría justificarse (3. a). Si se trata de filtrados públicos o privados no controlados por el usuario, los equipara a censura previa no admisible $(3 \mathrm{~b}$ ). El número 6 sobre «acceso a internet» «en ningún caso» acepta «interrupciones» o reducción de velocidad» de acceso masivas a toda o parte de la población «ni siquiera por razones de orden público o seguridad nacional» (6. b).

51 Sentencias del TJUE de 24 de noviembre de 2011, Asunto C-70/2010, Scarlet Extended vs SABAM y Asunto C-360/10 SABAM vs Netlog de 16 de febrero de 2012 
y protección de datos. El TJUE consideró que debe prevalecer la libertad de expresión y la protección de los usuarios que serían controlados y rastreados, así como la libertad de empresa frente a la imposición de estos controles «dado que se corre el riesgo de que el citado sistema no distinga suficientemente entre contenidos lícitos e ilícitos, por lo que su establecimiento podría dar lugar al bloqueo de comunicaciones de contenido lícito» ( $\left.\mathrm{n}^{\circ} 52\right)$.

Sin perjuicio de lo anterior, en razón de sentencia del TJUE de 27 de marzo de $2014^{52}$, sí que es posible que un juez solicite a un proveedor de acceso a Internet que bloquee el acceso de sus clientes a un sitio web que vulnera los derechos de autor. Al menos se requiere que las medidas de bloqueo de acceso a los usuarios «no priven inútilmente a los usuarios de Internet de la posibilidad de acceder de forma lícita a la información disponible» ( $\mathrm{n}^{\circ}$ 63) y que «tanto los internautas como también el proveedor de acceso a Internet deben poder hacer valer sus derechos ante el juez» $\left(\mathrm{n}^{\circ}\right.$ 54). No obstante, para poder ordenar estas medidas no es necesario probar que los usuarios del servicio acceden efectivamente a los contenidos ilegales.

Y en 2019 fue muy polémico y se estuvo muy cerca de que se obligara a establecer de mecanismos automatizados de filtrado y control del contenido subido en las plataformas. No obstante, ello no se expresa finalmente en la nueva Directiva (UE) 2019/790, de 17 de abril de 2019 sobre los derechos de autor y derechos afines en el mercado único digital. ${ }^{53}$ La cuestión ha quedado para el futuro debate jurídico. El mismo debe realizarse siempre sobre el punto de partida de las garantías a los límites de las libertades informativas y la potencial intensidad restrictiva y masiva que pueden tener estas medidas. Desde 2018 hay que tener en cuenta la Propuesta de Reglamento europeo para la prevención de la difusión de contenidos terroristas en línea (COM/2018/640 final). La misma impone a los proveedores "medidas proactivas", incluyendo "el uso de instrumentos automatizados" para la detección (art. 6), si bien, se regulan diversas garantías.

\section{IV.- ESPECIALES GARANTÍAS JUDICIALES, DE AUTORIDADES INDEPENDIENTES Y DE TRANSPARENCIA}

\section{1.- Exigencias de garantías judiciales y de transparencia en Derecho europeo}

A continuación, se sintetizan y reconstruyen lo que cabe considerar que son garantías exigibles de control judicial o por autoridad independiente. Las mismas se

52 Sentencia TJUE de 27 de marzo de 2014 asunto C 314/12 UPC Telekabel Wien GmbH / Constantin Film Verleih GmbH y Wega Filmproduktionsgesellschaft mb.

53 Se trató del artículo 7 y luego 13 (no en la versión final aprobada) que incluía de modo muy críptico dicha obligación.

(C) UNED. Revista de Derecho Político

N.o 108, mayo-agosto 2020, págs. 13-39 
derivan de la especial protección de los derechos y el recurso efectivo (art. $13 \mathrm{CEDH})^{54}$ y del debido proceso y acceso a la justicia (arts. 6 y 13 CEDH, 24 CE), así como resultan inherentes a la especial protección de las libertades informativas.

- Concretamente para internet la Declaración de 2011, expresa ( $n^{\circ}$ 6. c) que «la negación del derecho de acceso a Internet [...] constituye una medida extrema [....y en todo caso sólo cabe] siempre que haya sido ordenada por la justicia». La ya mencionada Decisión n 2009-580 de 10 de junio del Consejo Constitucional francés consideró inconstitucional la intervención administrativa no judicial para aplicar sanciones de corte de suministro de internet $\left(n^{\circ} 14\right)$, dado que implican una restricción de la libertad de expresión, que sólo lo puede hacer un juez.

El Consejo de Europa ha afirmado:

- La garantía de un control imparcial previo. El CDE 2016 exige garantías judiciales o de autoridad independiente e imparcial antes de aplicar las restricciones a internet y para examinarlas de forma continua (2.1.7). El artículo 1.3 bis de la Directiva 2002/21/CE que luego se comenta también establece la regla general del control judicial previo.

- Las decisiones deben poder revisarse con garantías de debido proceso ante un tribunal o autoridad independiente y, en todo caso, que se garantice la revisión judicial de sus decisiones (2.1.8). El acceso a los tribunales se reitera respecto de cualquier medida restrictiva de acceso y difusión de contenidos (art. 2.2. $4^{\circ}$ ). Se subraya la necesidad de procedimientos judiciales o administrativos «imparciales» $\left(\mathrm{n}^{\circ} 5^{\circ}\right)$, con posibilidad de recursos efectivos, que, además de judiciales pueden ser administrativos o ante instituciones nacionales de derechos humanos $\left(5.2^{\circ}\right)$.

- Además, la decisión judicial o de administración independiente «debe ser dirigida y específica» (targeted and specific) y con una ponderación clara dirigida a no impedir el acceso a internet $\left(2.4 .1^{\circ}\right)$.

En el ámbito de la UE se ha venido perfilando la necesaria garantía judicial. Ya en la STJCE de 6 de noviembre de 2003, caso Lindqvist ( ${ }^{\circ} 85$ y ss.) respecto de contenidos web se recordó que la ponderación entre la libertad de expresión debe realizarse en sede estatal, responsabilidad básica del juez nacional. En 2009 bajo fuerte polémica y en el último momento el Parlamento UE no aceptó la falta de autorización judicial para la desconexión de la red. El bloqueo se resolvió con la llamada "previsión de libertad» del artículo 1.3 bis de la Directiva 2002/21/CE: las medidas se han de adoptar con garantías judiciales, con un procedimiento «previo, justo e imparcial», con «derecho de los interesados a ser oídos», si bien con particularidades «en los casos de urgencia debidamente justificados».

54 Arrese Iriondo, M. N. (2009), «Artículo 13. Derecho a un recurso efectivo», en CEDH: comentario sistemático (por I. Lasagabaster coord.), Civitas, págs. 639-673. 
A las anteriores garantías hay que añadir la necesidad de transparencia. Ello es entre otras cosas una exigencia para que los afectados puedan ejercer los remedios y garantías frente a las restricciones. Así, el CDE 2016 obliga a que «El Estado proporcione información al público de manera oportuna y apropiada sobre las restricciones que aplica a la libertad de recibir e impartir información, como indicar sitios web que han sido bloqueados o de los cuales se eliminó información, incluidos detalles de la base legal, la necesidad y justificación de tales restricciones, la orden judicial que las autoriza y el derecho de apelar.» $\left(2.2 .5^{\circ}\right)$.

Lenski recuerda para Alemania que como estas restricciones de internet suelen tener lugar en secreto, por lo que del derecho de acceso a la justicia y debido proceso (artículo 19. $4^{\circ}$ Ley Fundamental) se deriva un deber de comunicación inmediata. Además, afirma una garantía objetivo-funcional: a través de la transparencia es viable un debate público, en el que se efectúe la ponderación democrática responsable y eficaz entre libertad y seguridad, y así se logre efectividad donde el desequilibrio de poder es más grande entre accionante y afectado ${ }^{55}$.

Las garantías de transparencia respecto de filtrados automatizados de contenidos se van incluyendo en legislaciones recientes contra la desinformación y el odio en internet, en cierta conexión con las garantías frente a decisiones automatizadas (art. 22 Reglamento (UE) 2016/679 de protección de datos) ${ }^{56}$.

\section{2. - Las necesidad de superar dudas constitucionales y legales en España de la necesidad de garantía judicial}

Como se ha adelantado en la arena nacional es muy necesario revisar y especialmente actualizar las garantías constitucionales de las libertades informativas frente a las restricciones de internet. Llama la atención no tanto la muy deficiente actuación legislativa, sino la especial ignorancia -o más bien evasión- del TC de estas cuestiones.

La situación en España dista de ser clara constitucional, legal y jurisprudencialmente y, además, ha sido social y políticamente conflictiva. El artículo 8 Ley 34/2002 ya hizo referencia a la «autoridad competente» (sin especificar si judicial o adminis-

55 Lenski, S., «Libertad y seguridad en el mundo digitalizado - protección nacional de los derechos fundamentales y vigilancia internacional de datos», AA.VV. (2017), Las tensiones entre libertad y seguridad, Grupo Editorial Ibáñez- U. Santo Tomás- U. Konstanz, Tunja (Colombia), pp. 257-268, pp. 263 y ss. cita p. 264.

56 Ver Declaración Conjunta sobre libertad de expresión y «Noticias Falsas», Relatores de la libertad de expresión de 3 de marzo de 2017, en concreto $\mathrm{n}^{\circ} 4$ b) para intermediarios. http://www.oas.org/ es/cidh/expresion/showarticle.asp? artID =1056\&lID $=2$.

Ver art. 11 LOI n $^{\circ} 2018-1202$ de 22 de diciembre contra la desinformación con obligaciones de transparencia si se usan algoritmos. También artículo 4 de la proposition de Loi para combatir el odio en internet de 2019 que obliga a intermediarios y a Conseil supérieur de l'audiovisuel a informar sobre las medidas que adoptan.

(C) UNED. Revista de Derecho Politico 
trativa) para adoptar medidas restrictivas. La Ley 2/2011, de 4 de marzo de economía sostenible (la convulsa «ley Sinde») reformó el artículo pero no despejó las dudas. El mismo dispone que «sólo la autoridad judicial competente» podrá adoptar medidas de restricción «En todos los casos en los que la Constitución y las Leyes reguladoras de los respectivos derechos y libertades así lo prevean de forma excluyente». Esto es, reconduce la cuestión al -indefinido- marco constitucional. La «ley Sinde» estableció un sistema para que una entidad no judicial ${ }^{57}$ pudiera decretar el cierre de webs que enlacen a contenidos ilícitos. Ahora bien, bajo presión social al menos pasó a requerirse una actuación judicial previa para la adopción de estas medidas ${ }^{58}$. En el trámite de aprobación de la conflictiva ley, el Consejo General del Poder Judicial y el Consejo de Estado ${ }^{59}$ el dieron por hecho que el artículo 20 CE impone la garantía judicial para impedir el acceso a una página web ${ }^{60}$. En casos excepcionales se han adoptado medidas individualizadas judiciales para impedir el acceso a internet con una muy dudosa base legal ${ }^{61}$ y que dudosamente pasarían los requisitos del TEDH.

El TC en modo alguno ha dejado claros los términos en que un control administrativo de contenidos es posible y, por lo que interesa, la posibilidad de una decisión de la restricción de acceso o de contenidos en internet por entidad administrativa no independiente. El interés se ha focalizado en la necesidad de una intervención judicial y en el artículo $20 \mathrm{CE}$ especialmente en los apartados $2^{\circ}$ y $5^{\circ}$ relativos a prohibición de censura previa y garantía judicial del secuestro. Se trata de garantías constitucionales de un mundo offline que generan no pocos problemas de encaje online. En todo caso, no puede eludirse una clara voluntad del constituyente de reservar a los jueces la garantía de la restricción del acceso y de los contenidos en la red.

En primer lugar, al secuestro sólo judicial de las publicaciones (art. 20. $5^{\circ} \mathrm{CE}$ ) quedaría sólo para la intervención de los soportes de la comunicación en internet, no para la posibilidad de un control administrativo de los contenidos difundidos ${ }^{62}$. Ahora

57 Se creó un órgano administrativo (la Sección $2^{\text {a }}$ de Propiedad intelectual) que tras un procedimiento puede resolver el cierre o bloqueo de una página web por permitir el acceso ilegal a contenidos protegidos por propiedad intelectual.

58 Así, se reformó el art. 122 bis Ley 29/1998: «Acordada la medida por la Comisión, se solicitará del Juzgado competente la autorización para su ejecución, referida a la posible afectación a los derechos y libertades garantizados en el artículo 20 de la Constitución.»

59 https://bit.ly/37mqwKv y https://bit.ly/3bAPYQ4

${ }^{60}$ En 2010 lo analicé en http://www.cotino.es/2010/03/consejo-de-estado-ley-de-economia-sostenible-y-cierre-de-webs/

${ }^{61}$ Polémicas sentencias Juzgado de lo Penal no 2 de Huelva de 17 de octubre de 2012 impuso a los proveedores de acceso a internet de todo el país la prohibición de facilitar a condenado por delito sexual acceso a Internet. En otro marco, la Audiencia Provincial de Barcelona en su sentencia 470/2013 de la Secc. $15^{\text {a }}$, de 18 de diciembre de 2013 , ordenó al operador de telecomunicaciones suspender «de inmediato y de forma definitiva la prestación del servicio de acceso a Internet» a uno de sus usuarios, aplicando discutiblemente los arts. 138 y 139. 1. h) de la Ley de Propiedad Intelectual

${ }^{62}$ Cabe recordar que no es aplicable por ejemplo al precintado de una radio en ejecución de un acuerdo administrativo (STC 88/1995, de 6 junio). Asimismo, el TC no afrontó desde el secuestro judicial la facultad de Correos para no distribuir revistas pornográficas (sentencia 52/1995, de 23 febre- 
bien, en muchos supuestos de intervención, filtrado o bloqueo de internet concurrirá también la garantía judicial expresa de la intervención de las comunicaciones del artículo $18.3^{\circ} \mathrm{CE}$ ). En todo caso cabe recordar que la STC $187 / 1999$, FJ $6^{\circ}$ vino a deducir del art. $20.5^{\circ} \mathrm{CE}$ que un poder público no judicial no puede adoptar medidas que impliquen un control crítico de los contenidos. Señala García Morales ${ }^{63}$ que la interrupción de un servicio o la retirada de un contenido en internet pueden representar una gravísima afectación de las libertades informativas equiparable al secuestro de una publicación. Para Rodríguez Teruel, del artículo $20.5^{\circ}$ CE se deriva una reserva estricta de jurisdicción ${ }^{64}$.

En segundo lugar, por cuanto a censura previa, la Declaración de 2011 considera que lo son los sistemas de filtrado de contenidos impuestos por gobiernos o proveedores de servicios comerciales y no son admisibles $\left(n^{\circ} 3\right.$ b). No obstante, la prohibición de censura previa no sería aplicable por cuanto el contenido al que se impide el acceso ya estaría disponible, por lo que en principio no sería una censura previa ${ }^{65}$. Por otra parte, no cabría aplicar la prohibición en los supuestos de bloqueos o filtrados impuestos por operadores no públicos. Asimismo, en los filtros no hay ponderación ni un examen manual de contenidos - como en la censura-. No obstante, García Morales apuesta por la necesidad de ampliar el concepto porque los filtros representan un control sistemático, general, planificado con ausencia palmaria de garantías ${ }^{66}$. En este punto cabe recordar que el TC ha definido también ampliamente a la censura como «cualesquiera limitaciones preventivas de su ejercicio», de la libertad de expresión, con carácter permanente y con un propósito censor (STC 187/1999, FJ 5º ), de igual modo ha prohibido «todos los tipos imaginables de censura previa, aun los más débiles y sutiles, que [...] tengan por efecto no ya el impedimento o prohibición, sino la simple restricción de los derechos de su artículo 20.1» (STC 52/1983, FJ $4^{\circ}$ ). Por ello, para esta autora cabría concebir la prohibición de censura frente a medidas que no solo hagan imposible la difusión ex ante, sino que impidan también la recepción por primera vez, ya que difusión y recepción pueden no ser ya simultáneas en las comunicaciones electrónicas ${ }^{67}$.

ro), en tanto quedaron otros canales de distribución -privados- se eludió afrontar la cuestión como secuestro por la administración.

${ }^{63}$ García Morales, M. J. (2013), «La prohibición de la censura en la era digital», en Teoría y realidad constitucional, $\mathrm{n}^{\circ} 31$, págs. 237-276, p. 255.

${ }^{64}$ Teruel Lozano, G. M. (2011), «El legislador y los riesgos para la libertad de expresión en internet: notas sobre las garantías constitucionales de la libertad de expresión en la LSSICE y en la Disposición final segunda del Proyecto de Ley de Economía Sostenible», en Cotino Hueso, L. (Ed.), Libertades de expresión e información en internet y las redes sociales: ejercicio, amenazas y garantías, PUV, Valencia, pp. 52-87, p. 81. En el caso de decisiones definitivas de cierre o bloqueo sería ya una reserva de jurisdicción a posteriori, que también afirma, pp. 81-82. Acceso en http:/www.uv.es/cotino/elibertades2010.pdf

${ }_{65}$ Teruel Lozano, G. M., «El legislador y los riesgos ..., cit., p. 81; García Morales, M. J., «La prohibición ... cit. pp. 254 y en especial, 267.

${ }^{66}$ Ibidem, pp. 263, 264, 267, 268 y ss.

${ }_{67}$ Ibidem, p. 268.

(C) UNED. Revista de Derecho Político

N. ${ }^{\circ} 108$, mayo-agosto 2020, págs. 13-39 
Como entre otros han señalado Boix o Doménech, las restricciones y controles administrativos de contenidos en internet llevan una deriva muy preocupante en los últimos años ${ }^{68}$. Afirman con especial voluntarismo que «el control y la represión de los posibles excesos expresivos corresponde al juez, y no al poder ejecutivo... [del art. $20 \mathrm{CE}$ se extrae] una preferencia constitucional por que sean los jueces los que lidien con la determinación, en cada caso, de qué concretos contenidos vulneran o no los límites establecidos por la Constitución, y desarrollados legislativamente, de la libertad de expresión» ${ }^{69}$. Doménech, con quién aquí se coincide, sostiene la reserva de jurisdicción bajo el principio de proporcionalidad y el riesgo que supone y derivada del propio art. $20 \mathrm{CE}^{70}-$

Para quien suscribe, del conjunto normativo internacional y constitucional y en particular en el ámbito de las libertades informativas, puede deducirse que el control público de contenidos y comunicaciones, así como la restricción de acceso a la información por poderes públicos exige la previa intervención de autoridad judicial o, cuanto menos y en su caso, de una autoridad independiente en un proceso con garantías suficientes. La garantía de jurisdicción o de autoridad independiente deriva principalmente de la libertad de expresión reconocida en el artículo 20. 1 CE interpretadas de conformidad al artículo 10.2 CE y teniendo en cuenta especialmente doctrina del TEDH. Las garantías en el ámbito del artículo $18.3^{\circ} \mathrm{CE}$ y, en particular de los apartados 2 y 5 del artículo $20 \mathrm{CE}$, no hacen sino apuntalar y reforzar esta tesis. Las garantías judiciales o de autoridad independiente deben darse aunque se mantuviera una interpretación anacrónica que excluyera estas concretas garantías judiciales para el mundo de las redes e internet.

Dicho lo anterior, no se puede obviar que la STC 86/2017, de 4 de julio. Se consideró constitucional que el Consell de l'Audiovisual de Catalunya - CAC (autoridad según su regulación, independiente) pueda adoptar por urgencia medidas cautelares o sanciones que implican el cese provisional o definitivo de la actividad audiovisual (art. 116 de la Ley 22/2005). Se trata de una sentencia más que cuestionable ${ }^{71}$ y que sería deseable superar en futuras decisiones para proteger efectivamente las libertades informativas del control público no del todo ajeno a criterios políticos. En todo caso, lo cierto es que el TC admite este tipo de medidas de urgencia porque se dan en el entorno con garantías de un procedimiento sancionador, con suficiente base legal,

${ }^{68}$ Doménech, G. (2019), «La policía administrativa de la libertad de expresión (y su disconformidad con la Constitución)», acceso en Academia.edu y Boix Palop, A. (2016), «La construcción de los límites a la libertad de expresión en las redes sociales», Revista de estudios políticos, n 173, pp. 55-112, en concreto, 103-104 y «El creciente protagonismo de las administraciones públicas en el control de contenidos audiovisuales y sus formas», en A. Boix Palop, J. M. Martínez Otero y G. Montiel Roig (eds.) (2017), Regulación y control sobre contenidos audiovisuales en España, Aranzadi, Cizur Menor, pp. 337-365.

${ }^{69}$ Boix Palop, A., «El creciente protagonismo de las administraciones... cit. p. 350.

70 Doménech, G., «La policía administrativa... cit. , pp. 8-12.

71 Ibidem, p. 12. 
bajo el principio de proporcionalidad, con urgencia justificada y recurribles judicialmente (FJ $\left.5 \cdot 1^{\circ}\right)$.

\section{V.- Para concluir. La inconstitucionalidad del «apagón», «mordaza» o «155» digital aprobado con el Real Decreto-ley 14/2019}

En medio de la convulsión política por la situación en Cataluña y al calor electoral de unas elecciones que se celebraban días después, el Gobierno aprobó el Real Decreto Ley 14/2019 el 31 de octubre, conocido como Decretazo, mordaza o 155 digital. En otros lugares he tenido la ocasión de analizar críticamente la nueva regulación del artículo 4. $6^{\circ}$ LGT $^{72}$. Este precepto reconoce al Gobierno la «facultad excepcional y transitoria de gestión directa o intervención podrá afectar a cualquier infraestructura, recurso asociado o elemento o nivel de la red o del servicio que resulte necesario para preservar o restablecer el orden público, la seguridad pública y la seguridad nacional.» ${ }^{73}$ Aunque se expresa en una terminología técnica que puede hacerlo pasar más desapercibido, la nueva regulación permite que el Gobierno, directamente o a través de sus consignas a los operadores, pueda cortar el servicio de comunicaciones e internet, deje la red inoperativa o controlar todo el flujo de datos de los usuarios. La intervención o gestión podría ser selectiva geográficamente, incluso imposibilitando o afectando a ejercicio masivo de derechos en espacios o zonas delimitadas. La afectación puede ser global, a toda la población, sectores geográficos e incluso selectiva por colectivos de usuarios delimitados o por tipos de conversaciones, mensajería, correos, etc. Puede llegarse a condicionar el acceso a webs, aplicaciones u otros servicios de la sociedad de la información. También y por supuesto, la actuación del gobierno puede ser reducir la velocidad de internet, también según criterios geográficos o según qué tipo de servicios.

Esta legislación restrictiva se lleva a cabo a través de un Decreto-Ley. Más allá de su dudosa urgencia y necesidad, sobre todo para quien suscribe, el Decreto-Ley «afecta» sin duda a libertades informativas pues puede conllevar materialmente que no puedan ejercerse, lo cual es una regulación sustancial prohibida a un Decreto-Ley.

$\mathrm{Y}$ lo que es peor, esta capacidad excepcional de intervenir ilimitadamente internet por el Gobierno se da sin garantía alguna. La reciente STC 76/2019, de 22 de mayo

72 Con amplitud analizo la cuestión en «La (in)constitucionalidad de la «intervención», «mordaza» o «apagón» de las telecomunicaciones e internet por el Gobierno en virtud del Real Decreto-Ley 14/2019», en Revista General de Derecho Administrativo, RGDA Iustel, no 54 mayo 2020. Una visión general crítica en Boix Palop, A. (2019), «El Decret llei 14/2019 i la mordassa digital - Andrés Boix Palop», blog de la Revista Catalana de Dret Públic, https://eapc-rcdp.blog.gencat.cat/2019/12/18/el-decret-llei-14-2019-i-la-mordassa-digital-andres-boix-palop

${ }^{73}$ Hay que tener en cuenta también las medidas cautelarísimas de la nueva versión del artículo 81 LGT. Me remito a mi estudio al respecto. En buena medida también pueden ser consideradas inconstitucionales a salvo de una interpretación muy favorable para intentar aplicar el régimen de garantías generales de estas medidas del art. 56.2 Ley 39/2015 así como otras garantías del Derecho europeo.

(C) UNED. Revista de Derecho Político 
$\left(\mathrm{FJ} 8^{\circ}\right.$ ) sobre perfilado de datos por partidos políticos culmina un proceso de alta exigencia de calidad normativa para limitar derechos. Pues bien, el nuevo artículo 4. $6^{\circ}$ LGT ni de lejos cumple con estos estándares de calidad, máxime siendo que la norma no prevé actuación judicial alguna. Que se trate de restricciones para la protección de la defensa, seguridad y orden puede flexibilizar algo el «margen de apreciación nacional» de un Estado que controla el TEDH y las mismas garantías constitucionales. Pero no las hace desaparecer. Y en la nueva regulación no se atisba ni de lejos un mínimo cumplimiento de las garantías aquí expuestas y especialmente fijadas en la STEDH Ahmet Yildırım c. Turquía de 18 de diciembre de 2012, o expresadas en la CDE 2016. Así, una potencial intervención del gobierno no se vincula a periodo temporal máximo, ni se determina un órgano que la adopte con garantías y análisis de impacto. Tampoco se delimitan y gradúan las posibilidades de actuación, ni se anuda a las necesidades, riesgos y peligros. No hay control o decisión previa por órgano judicial o autoridad independiente, y lo que es peor, ni existen mecanismos ex post, ni se fija periodo temporal alguno para la revisión de la decisión, ni por quien la adopta, ni por un órgano externo. No hay garantía judicial -o de autoridad independiente- alguna prevista, ni control judicial específico. Y el juez que hubiera de controlar las medidas adoptadas lo habría de hacer con un margen de indeterminación muy amplio e inadmisible para el TEDH. Asimismo, tampoco hay garantía mínima de transparencia de las decisiones y acciones que se adopten que permitan ejercer las garantías por los afectados, al tiempo de un debate público.

Hay que esperar que no se tenga que aplicar dicho precepto. La contaminación política del Decreto-Ley 14/2019 ha llevado a que ningún partido nacional que podía presentar recurso de inconstitucionalidad lo haya hecho. Y tampoco el Defensor del Pueblo, pese a la solicitud por asociaciones y especialistas, como quien suscribe ${ }^{74}$. No obstante, ha animado a una mejora normativa. Como se anunció, el Govern de la Generalitat de Cataluña el 29 de enero 2020 ha un presentado recurso de inconstitucionalidad $^{75}$. También el Gobierno Vasco el 21 de enero de 2020, si bien, haciendo uso del articulo 33.2 LOTC Constitucional abriendo la vía de la negociación. Cabe recordar en este sentido que Podemos afirmó un acuerdo político ${ }^{76}$ con el Gobierno para la modificación del Decreto-Ley por el cual se añadiría que «en ningún caso esa intervención [del Gobierno] podrá suponer una restricción de los derechos [...] además de estar sometida la decisión a control judicial inmediato» (letra d). Se afirma también un «control judicial inmediato» para las decisiones de concesión o denegación (letra

\footnotetext{
${ }^{74}$ Registrado como no expediente 20000639. AA.VV., Solicitud al Defensor del Pueblo de recurso de inconstitucionalidad frente al Real Decreto-ley 14/2019, 16 de enero de 2019, acceso en https://bit.ly/2OujRaz o en https://bit.ly/2S090aL

75 Acuerdo SIG20PRE0066. Cabe destacar el ejemplar Dictamen 6/2019, de 30 de diciembre del Consell de Garanties Estatutaries de Cataluña de más de cien páginas, en catalán https://www.cge.cat/ admin/uploads/docs/20200102142636-1.pdf

76 Puede seguirse el texto del acuerdo enperfil «Podemos Periodismo y Medios de Comunicación», de 27 de noviembre, https://bit.ly/2uhP6ik
} 
a) y en las medidas cautelarísimas del también polémico artículo 81 LGT, así como especial motivación (letra b). Algo es; aunque habría que esperar una redacción y sistema de garantías del derecho de acceso que cumpla más claramente con las que son exigibles internacional y constitucionalmente. Igualmente, resultaría especialmente de interés que el TC dictase una pronta sentencia, como lo hizo en el caso de la STC 76/2019 sobre perfilados políticos, que en cuatro meses desde el recurso hubo sentencia. Para quien suscribe, dicha sentencia habría de ser de inconstitucionalidad, pero en todo caso y con independencia del sentido de la misma, la argumentación del TC es necesaria para contar con un marco constitucional mucho más claro sobre la garantía del acceso a internet, algo esencial para las personas y protegible como derecho humano y fundamental. La llegada sobrevenida del maldito coronavirus ciertamente nos recuerda que la seguridad puede ser legítimo motivo para restringir derechos y libertades. Pero también nos obliga a agudizar las exigencias y garantías frente a posibles desvíos y abusos de poder público, más aún ante veladas amenazas de controles de redes y contenidos. Ello precisamente debe impulsar a revisar esta deficiente legislación que puede poner en peligro acceso a internet y a sus contenidos.

Title:

Online-offline. Guarantees for Internet access and for disconnection, blocking, filtering and other restrictions on the network and its content

\section{Summary:}

I.- The hybrid guarantees of Internet access. II.- The varied international, European and Spanish regulation of Internet access restrictions. III.- The guarantees against Internet access restrictions, blocking or filtering. IV - Special judicial guarantees, or guarantees by independent authorities. V.- To conclude. The unconstitutionality of the digital «blackout» or «gag» approved with Royal Decree Law 14/2019

\section{Resumen:}

Internet es un nuevo paradigma y su acceso ha pasado a ser una necesidad esencial humana que debe estar garantizada como derecho humano y con protección constitucional iusfundamental. Este derecho de acceso a internet va tomando forma a partir esencialmente de las libertades informativas. El análisis intenta construir y conformar las muy variadas garantías de muy diversa naturaleza que se van destilando para garantizar el libre acceso a internet, así como su dimensión presta-

(C) UNED. Revista de Derecho Politico 
cional o social y las obligaciones para garantizar el acceso que asumen los poderes públicos directamente o a través de operadores de comunicaciones. De la mano de la UE, la regulación española de telecomunicaciones ha sido la más seria hasta la fecha para la garantía del servicio público del acceso a internet como «servicio universal» (Tít. III, arts. 23-28 LGT). El emergente derecho de acceso se perfila también en negativo a partir de muchas regulaciones de las restricciones de internet en la regulación internacional, europea y española, un terreno relativamente opaco bajo el velo de la regulación técnica y de órganos sectoriales. En todo caso, se ha sostenido que las dudas de constitucionalidad de esta normativa dependerán de la concreta aplicación de la normativa. La naturaleza de derecho fundamental o humano se perfila con mayor claridad a la hora de analizar las garantías frente al apagón, desconexión, cierre, bloqueo, filtro, u otras restricciones de acceso a internet y sus contenidos. Ahí se aprecia más nítidamente la clásica dimensión negativa de las libertades informativas. No obstante, es necesaria una actualización y determinación de estas garantías y se ha intentado construir las mismas en razón del Derecho Europeo. En particular se ha subrayado el necesario protagonismo judicial para la restricción a internet y sus contenidos. El TEDH, el Consejo de Europa, y más tímidamente el Derecho de la UE, ya han avanzado mucho fijando tales garantías, pese a que en España ni la legislación ni la jurisprudencia parezcan percibirlo. Las garantías que aquí se sostienen derivan de las libertades informativas (art. 20. $1^{\circ} \mathrm{CE}$ ) interpretadas merced al artículo $10.2^{\circ} \mathrm{CE}$. En todo caso, se ha expuesto que el Derecho Constitucional español tampoco ha actualizado para internet las fuertes garantías que previó el constituyente en 1978. Aquí se aboga por una actualización digital de la prohibición de censura o del secuestro judicial de las publicaciones. El legislador español no se toma la cuestión en serio. El artículo 8 Ley 34/2002 sigue suscitando muchas dudas respecto de qué tipo de autoridad puede restringir internet y el artículo 81 Ley orgánica 3/2018 reconoce un derecho de acceso a internet vacuo o simbólico, y además no es de carácter orgánico. Finalmente se concluye que el nuevo artículo $4.6^{\circ} \mathrm{LGT}$ aprobado al calor de elecciones y máxima tensión política, no cumple ni de lejos los estándares de calidad normativa ni las garantías que aquí se han sostenido, además de incumplir las exigencias del artículo 86 CE. Además del Gobierno de Cataluña, el Gobierno Vasco lo ha hecho abriendo la posibilidad de negociaciones, por lo que cabe una reforma normativa también apoyada por partido de gobierno. Sin perjuicio de ello, sería deseable a una pronta declaración de inconstitucionalidad por el TC, que sirva, además, para actualizar su deficiente doctrina en la materia.

\begin{abstract}
:
The Internet is a new paradigm and access to it has become an essential human need; this must be guaranteed as a human right and with constitutional protection. This right of access to the Internet is taking shape essentially on the basis of the freedom of information. The guarantees of free access to the Internet have been analysed, as well as its social dimension and the obligations to guarantee universal access assumed by public authorities directly or through communications operators. In particular, based on the classic negative dimension of information freedo-
\end{abstract}


$\mathrm{ms}$, the guarantees against blackout, disconnection, closure, blocking, filtering or other restrictions on access to the Internet and its contents have been specified. In particular, the necessary judicial role for the restriction to the Internet and its contents has been underlined. The ECtHR, the Council of Europe and, more timidly, EU law, have already made great progress in establishing such guarantees. The guarantees that the author affirms derive from the freedom of information (art. 20. 1 EC) interpreted through article 10. 2 EC. In any case, it has been stated that Spanish Constitutional Law has not updated for Internet the strong guarantees provided by the Constituent in 1978. The author maintains the need for an digital update of the prohibition of censorship or the judicial sequester of publications. As stated, the Spanish legislator does not take the issue seriously. Article 8 Law $34 / 2002$ still raises many doubts as to what kind of authority can restrict the Internet. Article 81 Organic Law 3/2018 recognises a vacuous and symbolic right of access to the Internet, without organic legal nature. Together with the EU, the Spanish telecommunications regulation has been the most serious to date for guaranteeing the guarantee of internet access as a «universal service» (Title III, arts. 23-28 LGT). Internet restrictions on international, European and Spanish regulation, have been examined, a relatively opaque scope. It is affirmed that the doubts of the constitutionality of this regulation will arise with regard to their concrete application. However, the new article 4. $6^{\circ}$ LGT, approved in the heat of elections and maximum political tension, does not comply by far with the standards of regulatory quality nor the guarantees that have been maintained here, in addition to failing to comply with the requirements of article 86 EC. Governments of Catalonia and Basque Country have appealed. The author would like an early declaration of unconstitutionality by the Constitutional Court, which will also serve to update its poor doctrine in this area.

\section{Palabras clave:}

derecho de acceso a internet, restricción, bloqueo o filtrado de internet, libertad de expresión e información, garantías judiciales

\section{Keywords:}

right of access to the Internet, restriction, blocking or filtering of the Internet, freedom of expression and information, judicial guarantees

(C) UNED. Revista de Derecho Politico 
